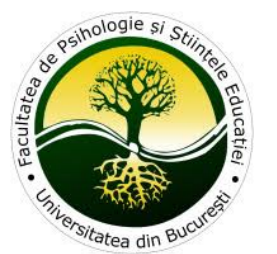

\title{
The role of locus of control and self-perception in the relationship between cyberbullying and depression, anxiety and stress in emerging adults
}

\author{
Popoviciu Cătălina Maria
}

University of Bucharest

\section{ARTICLE INFO}

Article history:

Received 20-February-2019

Accepted 20-April-2019

Available online 01-May-2019

This article should be cited as: Popoviciu, C. M. (2019). The role of locus of control and self-perception in the relationship between cyberbullying and depression, anxiety and stress to emerging adults. Studia Doctoralia. Psychology and Educational Science, 10, 4-17.

This is an open access article under the CC BY license (http://creativecommons.org/licenses/by/4.0/).

University of Bucharest, Department of Psychology, 90 Panduri Av, Bucharest, RO.

Tel.: +40 (0) 31-425.34.45

E-mail address: catalina.popoviciu@gmail.com

\section{ABSTRACT}

The present study aims at identifying the mediator role of the self-perception and the moderator role of locus of control in the relationship between cyberbullying and depression, anxiety, and stress symptoms. Seventy-two emerging adults between 20 to 25 years old were included in the study, filling in a series of measuring instruments for cyberbullying, self-perception, locus of control and depression, anxiety, and stress symptoms. The results were statistically significant in terms of the role of selfperception as mediator in the relationship between cybervictimization and depressive symptoms. Moreover, statistical results show that the global self-worth dimension of the self-perception construct and the school competence dimension are also mediators of the relationship between cyber-victimization and depressive symptoms. An increased level of cyber-victimization causes a low level of self-perception, which will cause an increased level of depression, anxiety, and stress symptoms. As regards the moderator role of locus of control, the results were not statistically significant in the case of the sample included in the study, locus of control does not moderate the relationship between cyberbullying and depression, anxiety and stress symptoms.

Keywords: cuberbullying, self-perception, depression, anxiety, stress

\section{INTRODUCTION}

With technological developments, communication systems and human interactions have received a distinct form. Individuals use smartphones to communicate with each other or to see each other, form their virtual individualities, and try to grow their social position and power daily in a virtual world that has no rules. The use of modern technologies for the young population has demonstrated its advantages over time, but the reduced ability to manage 
virtual society reveals specific vulnerabilities and puts young adults in the face of a relatively recent phenomenon: cyberbullying.

Defined as a deliberate aggressive act made by a group or a person, repeated over time, using modern technology to harm a person who cannot defend himself (Campbell \& Bauman, 2018), cyberbullying is perpetuated by sending threatening messages, humiliating images, stealing virtual identities, excluding someone from online groups, intimidating someone or spreading false rumors about someone (Nixon, 2014). Cyberbullying behaviors can take place both through social media, online applications, email, and mobile phones or text messages (Nixon, 2014).

Recent studies argue the need to see cyberbullying beyond the traditional bullying, separating them from both terminological and conceptually point of view, because cyberbullying has different characteristics and more profound effects than the traditional bullying, already studied for decades in the literature (Vranjes, Baillien, Vandebosch, Erreygers, \& Witte, 2018). According to the literature, in addition to the intentionality, repetition, power imbalance, common characteristics with the traditional bullying (Tiffany, 2018), cyberbullying also involves the use of modern technology for perpetuation, anonymity, infinite audience, possibility for perpetuation of the aggressive act 24/7 and the physical distance separating the victim from the aggressor (Patchin \& Hinduja, 2010).

\section{Cyberbullying and emerging adults}

Almost twenty years ago, Jensen Arnett (2000) proposed a new period in the development stages. She said that in modern industrialized society, between the period of adolescence and the adult period, there is an interim period, stretching between about 18 and 25 years old (Arnett, 2000). She proposed the term "emergent maturity" or "emerging adults," illustrating five essential characteristics of people in this development period: exploring identity, instability, selfcentered, experimentation of possibilities and feelings of being in the middle (Arnett, 2000).

The existing studies on the population of emerging adults argue that they are similar to both adolescents and adults, and are somewhere in between the two periods (Arnett, 2000). The areas of interest of emerging adults, similar to those of adolescents, refer to sexual relations, social identity, social position, unrealistic expectations towards the workplace, but from adults they have more introspection and reflect on their person (Arnett, 2000).

Although the literature on cyberbullying phenomenon is growing continuously, the samples covered in most studies are made up of children and adolescents, and the population of emerging adults is still a little exploited.

However, the existing studies in the emerging adult population, age coinciding with the status of university students, show that they also experience the cyberbullying phenomenon (Gibb \& Devereux, 2016), either as a victim or as a perpetrator.

Even though in literature the age period coinciding with the development period of the emerging adults it is referred to as the period of "young adults" or "adults", the present work conceptualizes the age period between 18 and 25 years old as the period for emerging adults with its implications for their psychological development. However, the past studies in the field will be presented with the conceptualization of emerging adults as it is carried out in the study.

A systematic review of the existing empirical studies in the literature on cyberbullying and young adults show that the majority are focused on samples consisting of university students ( $N=19)$ (Jenaro, Flores, \& Frías, 2018).

Also, the most common age limits in the existing studies in the literature are between 18 and 29 years old, the majority coming from the United States of America, and at that time, Romania had very few studies on the issues of cyberbullying for the said population (Jenaro et al., 2018).concept of self regulation is one that controls human behavior, thus combining the cognitive component with the behavioral. Criticism of the concept was primarily focused on its operationalization. The self-regulation system is built from various difficult-to-integrate functions (Carver, 1990). Despite the criticism, the concept relates to many aspects of everyday life (Perry et al, 2006) and should not be neglected.

\section{Cyberbullying prevalence among emerging adults}

Statistics suggest that one in five teenagers face cyberbullying once in a lifetime (Patchin \& Hinduja, 2010), and between the year 2000 and the year 2010, cyberbullying episodes in terms of adolescents have risen from $6 \%$ to $11 \%$ (Alhujailli \& Karwowski, 2019).

According to the literature, the prevalence of cyberbullying in young adults is higher when they are included in educational systems and begins to decline in the labor market, but does not disappear, the organizational climate plays a crucial role in the perpetuation of the phenomenon (Forssell, 2016; Hong, Chien-Hou, Hwang, $\mathrm{Hu}$, \& Chen, 2014).

\section{Cyberbullying effects on emerging adults}

The existing studies in the literature suggest that cyberbullying impacts the mental health of young adults, but the victims are not affected in the same way, with differences being due to certain characteristic situations, such as social support, emotional intelligence, empathy, coping styles or agreeability (Ak, Özdemir, \& Kuzucu, 2015; Doane, Pearson, \& Kelley, 2014; Elipe, Mora-Merchán, OrtegaRuiz, \& Casas, 2015).

The most common effects of cyberbullying in young adults are depressive symptoms (Mitchell et al., 2018), low psychological well-being (Tennant et al., 2015), decreased productivity (S. N. Mitchell \& Hoff , 2009), substance use 
(Selkie, Kota, Chan, \& Moreno, 2015), and low self-esteem (Brack \& Caltabiano, 2014; Patchin \& Hinduja, 2010).

Regarding the adult population in the organizational environments, the long-term effects of cyberbullying are associated with dissatisfaction in the workplace, stress, low level of well-being (Farley, Coyne, Sprigg, Axtell, \& Subramanian, 2015). Studies show that promoting a positive organizational culture should be essential (France, Danesh, \& Jirard, 2013).

\section{Risk factors associated with cyberbullying in emerging adults}

One of the first identified risk factors is the involvement in risky electronic interactions (Doane, Boothe, Pearson, \& Kelley, 2016). Another risk factor is the excessive use of the online environment, leading to risky use opportunities (Clark, Werth, \& Ahten, 2012).

According to the literature, women experience increased stress towards men and are more vulnerable to certain types of cyberbullying and victimization (Bauman \& Newman, 2013), having more aggression acts in the virtual world (Behm-Morawitz \& Schipper, 2016).

Undeveloped social skills and communication skills, as well as undeveloped imagination, have been associated with an increased risk of involvement in the cyberbullying phenomenon (Seigfried-Spellar, O'Quinn, \& Treadway, 2015).

\section{Cyberbullying and depressive symptoms}

The evidence available in the literature supports the association between cyberbullying and depressive symptoms, especially on samples consisting of adolescents.

Bonanno and Hymel (2013) explored in a study the extent to which cyberbullying, compared to the traditional bullying, contributes to the development of depression and suicidal ideation. The results showed that the pervasive and repetitive nature of cyberbullying made those involved in the episode feel the lack of hope, which contributed to the development of depressive symptoms.

A systematic review conducted in 2015 (Bottino, Bottino, Regina, Correia, \& Ribeiro, 2015) shows that cyberbullying has been associated with depressive symptoms in several studies on children samples, and in other studies included in the review, cyberbullying has also been associated with suicidal ideation.

According to a research (Hamm et al. 2015), which included 34 studies, the majority from the United States (58.3\%) and performed on samples consisting of adolescents, showed that in ten studies included, cyberbullying was associated with depressive symptoms.

Some studies show that both cyberbullying victims and aggressors have similar levels in terms of depressive symptoms (Forero et al. 1999; Kaltiala-Heino et al. 1999 Apud Tomşa et al. 2013).

Another study conducted on a sample consisting of adolescents and young adults showed that the relationship between depressive symptoms and cyberbullying was stronger in high school students towards young adults (Kircaburun, Kokkinos, Demetrovics, Kiraly, \& Ggiffiths, 2018).

\section{Cyberbullying and anxiety symptoms}

A study conducted on a sample consisting of students aged 18 to 29 showed that there are correlates between cyberbullying and social anxiety on the population concerned (Içellioğlu \& Özden, 2014).

Another recent study investigating the relationship between cyberbullying and depressive and anxious symptoms in adolescents aged 11 to 15 years old showed that cyberbullying has a direct effect on depressive symptoms and anxiety, and this relationship is moderated by self-compassion (Chu, Fan, Liu, \& Zhou, 2019).

Another study conducted on a sample involving 92 university students from Romania from the University of Bucharest (Tomşa, Jenaro, Campbell, \& Neacsu, 2013), surprised their experience with the traditional bullying and cyberbullying, and results showed a significant association between anxiety and both forms of bullying.

Another recent evidence of the relationship between cyberbullying and anxiety is provided by a study that analyzed the retrospective experiences of adults who stutter with the cyberbullying phenomenon. The results showed that the victims of cyberbullying that does not stutter, as well as those who stutter, have elevated levels of depression, anxiety and stress compared to the group that has not been subjected to cyberbullying (Nicolai, Geffner, Stolberg, \& Yaruss, 2018).

\section{Cyberbullying and stress symptoms}

According to the Conservation of resources theory (COR) (Habfoll, 1989), a person experiences stress when threatened to lose something worth a lot, such as social interaction (Giumetti et al. 2013).

On the other hand, stress is considered to be a source of performance decline (Hancock, Warm, 2003).

Certain studies show that the social support offered by friends can help in releasing the stress that develops concurrently with the cyberbullying episode (Cohen \& Wills, 1985; Segrin, 2003 Apud Tokunaga, 2010).

The studies suggest that cyberbullying can produce both chronic (long-term) and acute (short-term) effects (Alhujailli \& Karwowski, 2019).

Cyberbullying can lead to an increased level of stress because this phenomenon threatens the individual's basal needs, i.e., the need for belonging (Williams \& CarterSowell, 2009). According to literature, cyberbullying can induce immediate stress responses, and repeated situations of cyberbullying contribute to the persistence of these responses (Alhujailli \& Karwowski, 2019).

According to a recent study, the victims of cyberbullying and those involved with double role in the episode (both role of victim and bully) reported symptoms of post-traumatic 
stress, indicating that the group consisting of adolescents who were both victims and aggressors, have an increased risk of developing post-traumatic stress disorder (Baldry, Sorrentino, \& Farrington, 2018). These results were also found in other recent studies that evaluated the risk of exposure to cyberbullying concerning adolescents (Chen et al., 2018; McHugh, Wisniewski, Rosson, \& Carroll, 2018).

A longitudinal study aimed at investigating the predictive relationship between cyberbullying and subjective symptoms of stress, as well as the role of biological markers of stress in this relationship, found that the victims of cyberbullying and those who are victims and aggressors in the same time, had elevated levels of cortisol secretion, as well as increased levels of perceived stress (GonzálezCabrera, Calvete, León-Mejía, Pérez-Sancho, \& Peinado, 2017).

\section{Cyberbullying and self-perception}

The theory of self-perception speculates that individuals get to know their attitudes, emotions, characteristics and subjective experiences, in principle, through the inferences they make from the external observations of their behaviors or from the circumstances in which these behaviors occur (Bem, 1972). Thus, self-perception refers to how individuals evaluate themselves and define themselves in various areas of their lives (Harter, 1999). According to Harter (1999), the self is both a social and a cognitive construct, and each evaluates himself differently depending on the different areas of his life.

Research on cognitive models in the case of depression has shown that negative self-perception plays a profound role in the development and maintenance of depressive symptoms, and studies show that there are associations between low self-esteem and depressive symptoms in children (Asarnow, Carlson, \& Guthrie, 1987). On the other hand, the literature shows that self-perception is a "buffer" in the face of stress and is a predictive factor of satisfaction with life, and Rutter (1985) shows that self-esteem and its determinants (social support, competence) that emerge from self-perception, mediates resilience to stress.

According to Rutter (1985), the positive perception of close relationships can diminish the effects of another unhealthy relationship. At the same time, the perception of competence in a field can protect the individual against the occurrence of disturbances.

According to the literature, the victims of cyberbullying assess their abilities and characteristics according to their cyberbullying situations, with lower confidence in their capacities and self-effectiveness (Heiman, OlenikShemesh, \& Eden, 2015).

Other studies show that due to the anonymity of cyberbullying, there are significant decreases in the positive self-assessment, self-observation, and social competence perception of the victims (Wade \& Beran, 2011).
According to the literature, aggressors misevaluate their abilities and have an erroneous perception of themselves, which predisposes them to engage in aggressive virtual acts (Baroncelli \& Ciucci, 2014).

Another study shows that the most significant impact of cyberbullying on victims was at the level of self-esteem and self-assessment (Price \& Dalgleish, 2010).

The present work aims at identifying the mediator role of self-perception in the relationship between cyberbullying and depressive, anxious, and stress symptoms. This paper has the following assumptions: H1) Self-perception mediates the relationship between cyberbullying and depression symptoms $\mathrm{H} 2$ ) Self-perception mediates the relationship between cyberbullying and anxiety symptoms H3) Self-perception mediates the relationship between cyberbullying and stress.

\section{Cyberbullying and locus of control}

Locus of control is used to describe the tendency of a person to attribute the circumstances of life either to internal causes or to external causes (Kaslow, Rehm, Pollack, \& Siegel, 1984). Rotter (1966) proposed that people with an internal locus of control believe that the results or situations that occur in their lives result directly from their efforts, capacities, and personal characteristics. They think they are the ones who control circumstances affecting their lives, while persons with an external locus of control consider that behavioral or situational outcomes are conditional on external factors such as luck, chance, or efforts of other persons, i.e., consider that they do not have control over the circumstances affecting their lives.

Internal locus of control has been associated with multiple positive outcomes that are critical in the development of a teenager, both in terms of professional outcomes and in terms of mental health (Ekstrom, 1986; Lachman \& Weaver, 1998).

According to the COR model (Hobfoll, 1989), locus of control is considered to be an essential resource for adapting to adverse situations. Individuals possessing an internal locus of control are predisposed to use productive coping mechanisms focused on the problem (Muller, Skues, \& Wise, 2017). Individuals characterized by an external locus of control report a high level of anxiety, feelings of sadness and loneliness, as well as high levels of stress, as they tend to focus on the adverse events in their lives and on self-inability to control them (Ye \& Lin, 2015; Hojat, 1982; Argyle, 2001).

Also, a study (Mahatanankoon \& O'sullian, 2008) shows that people who have an internal locus of control feel more comfortable using the Internet because they believe they are the ones who guide their behavior in the virtual world, while people with an external locus of control have a negative perception of modern technologies and do not feel in control when using the Internet or when they participate in social media sites. 
Research on the relationship between any form of bullying (traditional or cyber) and locus of control are few, but the existing ones focus, in principle, on traditional bullying and samples with children and adolescents. The present paper assumes that the results found on the relationship between traditional bullying and the locus of control are similar to cyberbullying.

Atik and Guneri (2013) discovered in their study on children aged 11 to 15 years old that the external locus of control is more strongly associated with the role of victim and the perpetrator separately, than with the role of bully/victim concurrently, the results showing that those who are involved in the episode of bullying tend to have an external locus of control over those who do not experience the episode.

According to the literature on cyberbullying in children and adolescents, the extent to which they cope with the stress resulting from the cyberbullying episode depends on the level of internal resources they have, referring to selfesteem and locus of control (Muller et al., 2017). Trivitis (2005) confirms in a juvenile delinquency study that locus of control influences how adolescents adapt to stress.

Another study (Ariso \& Reyero, 2014) underlines the idea that the victims of cyberbullying have an external locus of control, which leads to feelings of helplessness, illustrating the need for cognitive restructuring in the direction of internalization the locus of control.

According to the data presented from the literature, the present paper has as the second objective the identification of the role of locus of control in the relationship between

\section{METHODOLOGY}

\section{Participants and procedure}

This is a quantitative, non-experimental, correlational research. The design is cross-sectional, data being collected from participants in a single moment in time.

Seventy-two participants are included in this study, with the sample being represented by emergent adults aged 20 to 25 years $(m=21.44, S D=1.83)$.

As for the gender, the sample was composed of 61 women and 11 men, the percentage being $84.7 \%$ women and $15.3 \%$ men, being coded " $1=$ feminine" and " $0=$ male" $(m=.85$, $\mathrm{SD}=.36)$.

Participants come from both urban and rural environments. Thus, 57 participants come from the urban environment (79.2\%), and 15 participants come from rural areas (20.8\%). The procedure for selecting participants was based on convenience, using an electronic announcement.

\section{Instruments}

Socio-demographic data cyberbullying and depressive, anxious, and stress symptoms. This paper has the following assumptions: $\mathrm{H} 4$ ) External locus of control accentuates the level of depressive symptoms; H5) External locus of control accentuates the level of anxiety symptoms; H6) External locus of control accentuates the level of stress $\mathrm{H} 7$ ) Internal locus of control diminishes the level of depressive symptoms H8) Internal locus of control diminishes the level of anxiety symptoms H9) Internal locus of control diminishes the level of stress.

The present paper aims to answer the following questions:

1. Moderates locus of control the relationship between cyberbullying and depression, anxiety, and stress symptoms?

2. Does the self-perception occur in the relationship between cyberbullying and depression, anxiety, and stress symptoms, acting as a mediator?

Following these questions were established the following objectives:

1. Identify the moderator role of locus of control in the relationship between cyberbullying and depression, anxiety, and stress symptoms.

2. Identify the mediator role of self-perception in the relationship between cyberbullying and depression, anxiety, and stress symptoms

Questions related to age, gender, ethnicity, the most frequently used digital device (smartphone, tablet, laptop, computer, others) and the most frequently used online application (Facebook, Instagram, Youtube, Snapchat, Twitter, others).

\section{Cyberbullying}

To measure the independent variable this paper used the European Cyberbullying Intervention Project Questionnaire built by Brighi et al. (2012) and structurally validated crosscultural by Del Rey et al. (2015) containing 22 items on a Likert scale in 5 points (0-Never and 4-more than once a week). Items refer to different types of behaviors and actions that define cyberbullying and are divided into two dimensions: cyber-victimization and cyber-aggression. They were translated from English into Romanian language using the "Back-translation" method (e.g. "Someone said unpleasant things about me or insulted me through the Internet, online messages or text messages"- "Cineva a spus lucruri neplăcute despre mine prin intermediul Internetului, mesajelor online sau mesajelor text"). 
Concerning the reliability of the scale, in the studies (Casas, Del Rey, \& Ortega-Ruiz, 2013; Del Rey et al., 2015; HerreraLópez, Casas, Romera, Ortega-Ruiz, \& Del Rey, 2017), which measured cyberbullying phenomenon with this scale, were reported a Cronbach coefficients between .84 and .97 for both dimensions.

Following the completion of the pilot study, a Cronbach a of .75 was obtained for the entire scale. For the cybervictimization dimension was reported a Cronbach a of .64, and for the cyber-aggression dimension, a Cronbach a of .68. An item ("Someone altered the photos or videos of me that I posted online") was removed from the instrument for reliability reasons.

As regards the total sample included in the study, a Cronbach a of .92 was obtained for the entire scale. For the cyber-victimization dimension was obtained a Cronbach a of .80 , and for the cyber-aggression dimension was obtained a Cronbach a of .90 .

\section{Depression, anxiety, stress}

The dependent variables were measured using the DASS21 scale (Lovibond \& Lovibond, 1995), a set of three selfreport scales that measure the emotional states of depression, anxiety, and stress. The scale consists of 21 items, each dimension with seven items, on a Likert scale in 4 points $(0$ - it did not happen at all, in my case and 3-it happened very much, or for the most of the time). This scale aims to measure non-clinical symptoms of depression, anxiety, and stress. For depression, items refer to, lack of hope, lack of interest, devaluation, anhedonia, and inertia (e.g., "I felt that I had nothing to look forward to"). For anxiety, items refer to autonomic excitation, muscle tension, situational anxiety and subjective experience of anxious impairment (e.g., "I had the feeling of dryness of the mouth"), and in the case of stress the items refer to the difficulty in relaxation, nervous excitation, irritability (e.g., "It was hard for me to calm down").

About the reliability of the scale, in the literature were reported a Cronbach coefficients with variations between .90 and .95 for stress subscale, between .96 and .97 for depression subscale and between .84 and .92 for anxiety subscale ( Parkitny \& McAuley, 2010).

In the present study, the a Chronbach coefficient for the entire scale is .93 , for the depression scale is .87 , for the anxiety scale is .82 , and for the stress scale is .86 .

\section{Self-perception}

For the measurement of the mediating variable, the "Selfperception profile for college students" was used (Neeman \& Harter, 2012), a scale that conceptualizes university students as being in the psychological development period coinciding with emerging adults. The primary purpose of this scale is to create a suitable measuring instrument for people who are still integrated into the school field, are students or learners, areas that are of importance to adolescents, but have common areas with the adult population. The scale contains 13 subscales with specific domains such as creativity, intellectual ability, school competence, workplace competence, athletic competence, appearance, romantic relationships, social acceptance, close friendship relationships, relationship with parents, humor, morality, and general domain, that is, the global self-worth. The 12 subscales of the specific domains each contain four items, and the subscales referring to the global self-worth contains six items, in total, the scale having 54 items (Neeman \& Harter, 2012). The items were translated from the English language in Romanian with the "Back-translation" method changing the word "student" in "youngsters" (e.g., "Some students like the kind of person they are BUT Other students wish that they were different"- Anumitor tineri le place de ei înșiși, DAR Alți tineri și-ar dori să fie diferiți").

The participant is first asked to decide in which typology falls through the assertions described in the left and right side of the questionnaire (e.g., A) certain young people like themselves BUT B) Other young people would like to be different), and then decide whether the part he has chosen is "very true to him" or "almost true to him", the general procedure being the scoring of each item on a likert scale from 1 to 4, where one indicates low perceived competence or low suitability and four reflects a high level of competence and suitability(Neeman \& Harter, 2012). The questionnaire was conducted in this way in order to discourage desirable responses and strengthen honest responses, the present work using the same format in order not to alter the psychometric features of the questionnaire.

In terms of reliability, a Cronbach reported by the authors varies between .53 and .84 , six of the subscales being between .70 and .79 and three over .80 (Neeman \& Harter, 2012).

Following the completion of the pilot study on 30 participants, Cronbach a for the entire scale was .92, and for subscales between .58 and .86 (five subscales between .62 and .78 , a scale with .58 and seven subscales between .78 and .86)

As regards reliability for the total sample included in the study, a Cronbach is .92 for the entire scale. As for the subscales, a Cronbach varies between .59 and .86, the morality scale having a Cronbach a of .59 , five scales with variations between .63 and .70 , and seven subscales with variations between .70 and .86 .

\section{Locus of control}

For the measurement of the moderating variable was used Rotter's Locus of Control Scale (1996), translated and adapted by Dragoş Iliescu at the Faculty of Psychology and Education Sciences, University of Bucharest and was taken from the site www.researchcentral.ro. The scale is 
composed of 29 items with two options of response that represent sentences concerning the way of being and the opinions of the participants. Respondents are asked to choose between the two pairs of sentences exhibiting the one that best suits their vision of everyday life situations. For example, an item is displayed in the following way: "a) Children get into trouble because their parents punish them too much. b)The trouble with most children nowadays is that their parents are too easy with them- a) Copiii au necazuri pentru că părinții lor îi pedepsesc prea des b) Necazurile celor mai mulți copii în ziua de azi provin din faptul că părinții ii lasă prea liberi". A high score is an external locus of control, while a low score is an internal locus of control.

In the literature, a Cronbach varies between .70 and .76.

\section{Procedure}

In the first phase of the research, the pilot study was carried out on 30 participants aged 20 to 25 years $(m=23.03, S D=$ 1.60) for translating instruments and verifying their reliability. The pilot study was conducted between January and February 2019 and consisted of translating the instruments using the "back-translation" method and then, collecting the data for the pilot study. The European Cyberbullying Intervention Project Questionnaire and Self-Perception Profile for College Students instruments have been distributed online through the "Google Forms".

The results obtained from the pilot study were exemplified in the instruments section.

The next step consisted in making changes and distributing all instruments for measuring the variables of research. The data collection procedure was carried out from March 2019

\section{RESULTS}

In a first step in the preliminary analysis of the data, this research has used descriptive statistics that are reported in Appendix 1, presenting the mean, standard deviation and the coefficient of the confidence interval of the mean for each variable analyzed.

In order to achieve the first objective of the research, identifying the mediator role of self-perception in the relationship between cyberbullying and depressive, anxious and stress symptoms, and for testing the assumptions arising from the main objective, were carried out a series of mediation analyses having as predictors the two dimensions of cyberbullying, and as mediators the 13 dimensions of the self-perception, as well as the total self-perception.

Thus, for testing $\mathrm{H} 1$ ) the self-perception mediates the relationship between cyberbullying and depressive symptoms have been conducted a series of mediation analyses taking as predictors cyberbullying with both dimensions: cyber-victimization $(m=5.29, S D=4.29)$ and to May 2019, with participants being informed before testing that they would complete four questionnaires with an average duration of 25-30 minutes. The methods of collecting data were quantitative following the research design, based on questionnaires. The data was collected from the online environment via "Google Forms," where the specific variables measurement instruments were introduced. The questionnaire was made visible among young people aged 20 to 25 years to be completed. Participants were given the instruction of completing the questionnaires before each instrument, and they were instructed to complete when they understood the requirements, and for doubts, they were asked to contact the researcher. Fierce completion of the questionnaire, participants were able to read the informed consent form in order to achieve total transparency between the participant and the requirements of the study. Participants completed all questionnaires in a single work session, with data being collected in a single moment in time.

\section{Analyses}

In order to process the data collected from the 72 participants, the Statistical Package for the Social Sciences (SPSS) version 25 was used for descriptive statistics. The Jamovi 0.9.6.9 program was used for mediation and moderation analyses.

To have "a reasonable probability of confirming the hypothesis of research" (Popa, 2016, p. 16) was used G * Power 3.1, which calculates the power of the test, obtaining an apriori test power ( $d=5$ ) of $95 \%$ in a sample of 107 participants.

cyber-aggression ( $m=4.44, S D=5.62)$, and as a mediating variable, the total self perception $(m=145.97, S D=25.65)$, as well as its dimensions: the global self-worth $(m=16.29$, $S D=4.55)$, the job competence $(m=10.49, S D=2.75)$, school competence $(m=11.67, S D=2.65)$, social acceptance $(m=11.06, S D=3.05)$, appearance $(m=10.07$, $S D=3.69)$, parental relations $(m=11.92, S D=3.59)$, close friendship relationships $(m=10.97, S D=3.05)$, intellectual ability $(m=11.29, S D=3.43)$, morality $(m=12.24, S D=$ $2.67)$, romantic relations $(m=9.68, S D=3.40)$, humor $(m=$ $11.56, S D=3.01)$, creativity $(m=10,63, S D=3.16)$ and athletic competence $(m=8.19, S D=3.23)$, dependent variable being depressive symptoms $(m=7.69, S D=4.94)$.

As regards the mediator role of the total self-perception in the relationship between cyber-victimization and depressive symptoms, the result is statistically significant, the total selfperception mediates the relationship between cybervictimization and depressive symptoms $(a * b=.13, Z=2.24$, 
$p \leq .05$, Cl95\%: .01-. 25) the mediation percentage being 27.3\% (Table 1). Cyber-victimization negatively correlates with the self-perception $(-1.92, p \leq 0.5)$, and the selfperception correlates negatively with depressive symptoms $(-.07, p \leq 0.5)$. The results are also statistically significant for the following dimensions of the self-perception: the global self-worth $(a * b=.14, Z=2.31, p \leq .05, C 195 \%$.. 02-. 26), the percentage of mediation being $28.9 \%$ and school competence $(a * b=.11, Z=1.99, p \leq .05$, Cl95\%: .001-. 226), the percentage of mediation being $22.8 \%$ (Table 1 ). Cyber-victimization negatively correlates with global selfworth, and global self-worth negatively correlates with depression. Cyber-victimization negatively correlates with school competence (-. 22, $p \leq 0.5)$, and the school competence relates negatively to depressive symptoms ($.50, p \leq .05)$.

Concerning the cyber-aggression dimension of cyberbullying, the results were not statistically significant, the self-perception is not a mediator of the relationship between cyber-aggression and depressive symptoms.

For the testing of the $\mathrm{H} 2$ ) the self-perception mediates the relationship between cyberbullying and anxiety symptoms a number of analyses were performed, and in the case of total self-perception, the results were statistically significant $(a$ * $b=.12, Z=2.09, p \leq .05, \mathrm{Cl} 95 \%: .007-.244$ ) as regards the cyber-victimization dimension (Table 1), the percentage of mediation being $47.3 \%$, but not in relation to the cyberaggression dimension ( $a{ }^{*} b=.04, Z=1.13, p \geq .05, C 195 \%$ :-
.03- .12). Between cyber-victimization and self-perception a significant negative relationship was obtained $(-1.92, p \leq$. $05)$, and between total self-perception and anxiety symptoms also a significant negative relationship $(-06, p \leq$. 05).

Concerning the dimensions of the self-perception being mediators in the relationship between cyberbullying and anxiety symptoms, the results were not statistically significant, the relationship between cyberbullying and anxiety symptoms being, in this case, mediated only by the total self-perception and only for cyber-victimization dimension.

To test the H3 ) self-perception mediates the relationship between cyberbullying and stress, the results were statistically significant $\left(a{ }^{*} b=.11, Z=2.01, p \leq .05\right.$, Cl95\%: .003- .232) as regards the relationship between cybervictimization and stress, with total self-perception, as the mediator factor, the percentage of mediation being $57.7 \%$. This paper shows that between cyber-victimization and selfperception is a significant negative relationship $(-1.92, p \leq$ $.05)$, and between total self-perception and stress is still a significant negative relationship (- .06, $p \leq .05)$.

Concerning the cyber-aggression dimension, the results are not statistically significant, and in terms of the dimensions of the self-perception, they do not mediate the relationship between cyberbullying and stress. $p>.05$ ). Reliability coefficients can be seen in Table 1.

Table 1. Mediation estimates

\begin{tabular}{|c|c|c|c|c|c|c|c|}
\hline \multirow[b]{2}{*}{ Effect } & \multirow[b]{2}{*}{ Estimate } & \multirow[b]{2}{*}{ SE } & \multicolumn{2}{|c|}{ 95\% Confidence Interval } & \multirow[b]{2}{*}{ Z } & \multirow[b]{2}{*}{$p$} & \multirow[b]{2}{*}{$\%$ Mediatior } \\
\hline & & & Lower & Upper & & & \\
\hline$C V->P S->D$ & 0.136 & 0.0608 & 0.0168 & 0.255 & 2.24 & 0.025 & 27.3 \\
\hline $\mathrm{CV}->\mathrm{GW}->\mathrm{D}$ & 0.144 & 0.0624 & 0.0218 & 0.266 & 2.31 & 0.021 & 28.9 \\
\hline $\mathrm{CV}->\mathrm{SC}->\mathrm{D}$ & 0.114 & 0.0572 & 0.00155 & 0.226 & 1.99 & 0.047 & 22.8 \\
\hline$C V->P S->A$ & 0.126 & 0.0602 & 0.00790 & 0.244 & 2.09 & 0.036 & 47.3 \\
\hline CV $->P S->S$ & 0.1176 & 0.0584 & 0.00313 & 0.232 & 2.014 & 0.044 & 57.7 \\
\hline
\end{tabular}

$\mathrm{N}=72, \mathrm{p} \leq .05$

$\mathrm{CV}=$ cyber-victimization; $\mathrm{PS}=$ total self-perception; $\mathrm{GW}$ = global self-worth; $\mathrm{SC}=$ school competence;

$D=$ depressive symptoms; $A=$ anxiety symptoms; $S=$ stress

In order to achieve the second objective, the identification of the role of locus of control in the relationship between cyberbullying and depression, anxiety and stress symptoms, a series of moderations were performed to test the $\mathrm{H} 4$ ), $\mathrm{H} 5$ ), $\mathrm{H} 6), \mathrm{H} 7$ ), H8) and $\mathrm{H} 9$ ) hypotheses. The results are not statistically significant, locus of control is not a moderator factor in the relationship between cyberbullying and depression, anxiety and stress symptoms. 


\section{DISCUSSION}

The main objectives of the present study were to identify the mediator role of self-perception and the moderator role of locus of control in the relationship between cyberbullying and anxiety, depression, and stress symptoms.

Results show that in this research, self-perception is a mediator factor of the relationship between cybervictimization and depression, anxiety, and stress symptoms, but in the case of cyber-aggression, selfperception does not have a mediator role. According to the results, the relationship between cyber-victimization and self perception is a negative one, meaning that when it is an increased level of cyber-victimization, the self-perception has a low level, and the low level of selfperception causes an increased level of depression, anxiety, and stress symptoms, and a pattern of "U"shaped relationship can be identified. These results are consistent with the literature, which shows that, in the case of cyberbullying victims, self-assessment, and how they perceive themselves is negative.

On the other hand, the results provide a look in depth due to the dimensions of the self-perception. Thus, in the present study, global self-worth has the role of mediator in the relationship between cyber-victimization and depressive symptoms. An increased level of victimization determines low levels of self-worth, which leads to a grew up level of depressive symptoms. This result is consistent with the literature that states that the victims of cyberbullying have a low level of self-worth and that depression involves feelings such as lack of value and low self-perception.

On the other hand, according to the results, the perception of the educational competence of emerging adults is also influenced by cyber-victimization, being a mediator of the relationship between cyber-victimization and depressive symptoms.

The positive self-perception is a protective factor against the development of various disorders, but it is formed in interaction with the social environment and with reinforcements received in the various essential areas of the life of emergent adults. A deliberate, aggressive act such as cyberbullying that has the potential to be extremely damaging in the light of its characteristics affects the self-perception of emerging adults. They are in a transitional period between adolescence and adulthood, they are exploring their identity and form the perception of the self, and a deliberate, aggressive act on them threatens the stability of their individuality. This fact could also represent a reason why, in this paper, self-perception does not have a role in the relationship between cyberaggression and depressive, anxious, and stress symptoms. A bully is not directly affected on self- esteem and self-perception by the cyberbullying episode, influencing then the symptomatology.

On the other hand, according to the results, analyzing in the depth of the self-perception variable, only in the case of depression can be observed an effect of selfperception dimensions (global self-worth and school competence). A possible explanation would be that the global self-worth, the mediator of the relationship between cyber-victimization and depressive symptoms, is in strong relation to cyber-victimization because is the first factor affected by aggressive acts according to literature.

Taking into account the fact that the principal goal of emerging adults through modern technology and social media sites is to increase their social status and selfworth, cyberbullying imbalances this process. From an evolutionary perspective, the mate value is the sum of desirable characteristics that could make a potential partner consider another one to be a genetically qualitative person and a potential source of reproduction success, and a positive self-value could be a basic promotor of reproduction. Self-worth can influence the relationships with others and it can also influence the personal preferences for the choice of the partner, thus, the more developed and positive selfworth, the higher the chosen partner will be genetically qualitative. In emerging adults, being at the search stage of the potential partner for reproduction, a low self-value will also decrease the chances of finding the partner, and then, transmitting the genes and this could be an explanation of the development of depressive symptoms in this case. On the other hand, cyberbullying on victims can be seen as an act of invalidation of their genetic qualities and can be interpreted as an act of rejection by potential partners, which will make selfworth decrese and develop depressive symptoms.

School competence also intervenes as a mediator in the relationship between cyber-victimization and depressive symptoms, and an explanation of this can be given by the fact that, as it is found in the literature, the emerging adults are in the period that coincides with university studies, period of development of professional qualities and training of professional identity. Aggressive acts that target the quality of professional skills of cyberbullying victims can lead to high levels of depressive symptomatology, as vocational training in university years is among the most critical areas of interest of emerging adults, constituting the basis of a future career. Linking also to the evolutionary genetic quality discussed at the self-worth, school competence determines success in the career, which entails capacity to care for the future family, genetic qualities in a partner and an indication of successful reproduction to ensure the transmission of 
eyelashes further through the survival of children and the birth of grandchildren. This supposition can be dotted as the future direction of research.

Concerning the relationship between cyberbullying and self-perception and anxious symptoms and stress, a low level of global self-perception due to the cyberbullying episode concerning victims will affect the level of anxiety and stress, which will increase. By the fact that victims negatively assess their competences, they do not feel capable of managing the cyberbullying episode, the concern and fear of the aggressive act may arise, and it is impossible for them to relax, taking place the irascibility and the symptomatology of anxiety and stress can be highlighted.

According to the results, a statistically significant relationship about the dimensions of self-perception with cyberbullying and anxiety and stress was not highlighted in the population included in the sample of the study. An explanation may be the small volume of the sample included in the study. In the sample of this work, not all dimensions of the self-perception correlate statistically significantly with the variables of the proposed model due to the non-homogeneity of the sample and volume. The instrument used to measure self-perception can also be a cause of the results, because the method of completion is cumbersome, and certain expressions are not accessible to all.

As regards the second objective, the identification of the moderator role of locus of control in the relationship between cyberbullying and depressive, anxious and stress symptoms, the results were not statistically significant. An explanation could be the methodological aspects of the study, such as the number of participants. On the other hand, concerning the reliability of the locus of control scale, a Cronbach a of .74 is acceptable but not excellent value. At the same time, locus of control with cyberbullying is very poorly analyzed in the literature, but the existing studies say that an external locus of control accentuates the effects of cyberbullying. The relationship between variables was not identified in the present paper, is proposed for future studies to take into account the locus of the control concerning cyberbullying.

\section{Limitations and future directions}

The limits of the present study refer to methodological aspects in the first place. The use of the self-report cyberbullying measurement scales, not being able to render the characteristics of the phenomenon in its entirety, as well as the number of participants in the study. Also, being a non-experimental study, no causal conclusions can be drawn, it is necessary to carry out experimental, longitudinal studies, with a view to a deeper understanding of the phenomenon, as most studies are quantitative, based on self-report instruments. On the other hand, an impediment to the achievement of this study was the rather long time of completing the instruments by the participants, many of them giving up the trial.

The present study adds a plus in the literature by tackling the cyberbullying phenomenon on a sample represented by emerging adults. On the other hand, the novelty is the inclusion of self-perception as a mediator factor in the relationship between cyberbullying and depressive, anxious and stress symptoms, and locus of control as moderator. At the same time, the present study seeks to explain from another perspective the factors involved in the cyberbullying phenomenon, representing an additional step towards understanding the phenomenon discussed assiduously and controversial in the literature.

The present study also shows the importance of tackling prevention and intervention strategies regarding cyberbullying, geared towards developing a positive self-perception of the victims involved in the phenomenon.

Further studies should use larger samples consisting of emerging adults, use longitudinal studies, analyzing locus of control as a moderating variable on a larger sample. Also, in the present study, cyber-victimization and cyber-aggression were used as a continuous variable, it is necessary that future studies develop an instrument for measuring the dimensions of cyberbullying with well-established cut-off points, to classify victims and aggressors to validate the results better. The measuring instrument should also be validated and adapted to the population of emerging adults in Romania, as there is no such instrument until now.

\section{Conclusions}

The present study is a novelty in the scientific literature in Romania because, in recent years, the phenomenon of cyberbullying has taken a large scale and has been too little analyzed in the literature. The sample, represented by emerging adults, is rarely used in studies, most of them analyzing the phenomenon in adolescents and children.

Despite the methodological aspects to be resolved, the present study argues the need to implement prevention and intervention strategies aimed at optimizing the selfperception of emerging adults, victims of cyberbullying and developing coping strategies in order to prevent depression, anxiety, and stress symptoms. These strategies should aim at increasing the global self-worth that the emerging adult perceives, as well as the increasing of a positive perception of school competence. These strategies should be implemented 
both at the individual level and at the universities level, where emerging adults spend most of their time.

\section{REFERENCES}

Ak, Ş., Özdemir, Y., \& Kuzucu, Y. (2015). Cybervictimization and cyberbullying: The mediating role of anger, don't anger me! Computers in Human Behavior, 49, 437-443.

https://doi.org/10.1016/j.chb.2015.03.030

Alhujailli, A., \& Karwowski, W. (2019). Emotional and Stress Responses to Cyberbullying. In G. Di Bucchianico (Ed.), Advances in Design for Inclusion (pp. 33-43). Springer International Publishing.

Argyle, M. (2001). The psychology of happiness. Routledge: New York.

Arıcak, O. T. (2009). Psychiatric symptomatology as a predictor of cyberbullying among university students. Eurasian Journal of Educational Research (EJER), (34).

Ariso, J. M., \& Reyero, D. (2014). Reconsidering the scenario of cyberbullying: Promoting the internalization of the locus of control in adolescents through cognitive restructuring. Adolescent Psychiatry, 4(2), 98-103.

Arnett, J. J. (2000). Emerging adulthood: A theory of development from the late teens through the twenties. American psychologist, 55(5), 469.

Asarnow, J. R., Carlson, G. A., \& Guthrie, D. (1987). Coping strategies, self-perceptions, hopelessness, and perceived family environments in depressed and suicidal children. Journal of Consulting and Clinical Psychology, 55(3), 361-366.

https://doi.org/10.1037/0022-006X.55.3.361

Atik, G., \& Güneri, O. Y. (2013). Bullying and victimization: Predictive role of individual, parental, and academic factors. School Psychology International, 34(6), 658-673.

Baldry, A. C., Sorrentino, A., \& Farrington, D. P. (2018). Post-Traumatic Stress Symptoms Among Italian Preadolescents Involved in School and Cyber Bullying and Victimization. Journal of Child and Family Studies. https://doi.org/10.1007/s10826-018-1122-4

Baroncelli, A., \& Ciucci, E. (2014). Unique effects of different components of trait emotional intelligence in traditional bullying and cyberbullying. Journal of Adolescence, 37(6), 807-815.

https://doi.org/10.1016/j.adolescence.2014.05.009

Bauman, S., \& Newman, M. L. (2013). Testing assumptions about cyberbullying: Perceived distress associated with acts of conventional and cyber bullying. Psychology of Violence, 3(1), 27-38. https://doi.org/10.1037/a0029867
Behm-Morawitz, E., \& Schipper, S. (2016). Sexing the avatar: Gender, sexualization, and cyber-harassment in a virtual world. Journal of Media Psychology: Theories, Methods, and Applications, 28(4), 161-174. https://doi.org/10.1027/1864-1105/a000152

Bem, D. J. (1972). Self-Perception Theory. In L. Berkowitz (Ed.), Advances in Experimental Social Psychology (Vol. 6, pp. 1-62).

https://doi.org/10.1016/S0065-2601(08)60024-6

Bonanno, R. A., \& Hymel, S. (2013). Cyber bullying and internalizing difficulties: Above and beyond the impact of traditional forms of bullying. Journal of youth and adolescence, 42(5), 685-697.

Bottino, S. M. B., Bottino, C., Regina, C. G., Correia, A. V. L., \& Ribeiro, W. S. (2015). Cyberbullying and adolescent mental health: systematic review. Cadernos de saude publica, 31, 463-475.

Brack, K., \& Caltabiano, N. (2014). Cyberbullying and self-esteem in Australian adults. Cyberpsychology: Journal of Psychosocial Research on Cyberspace, 8. http://dx.doi.org/10.5817/CP2014-2-7

Campbell, M., \& Bauman, S. (2018). Reducing Cyberbullying in Schools: International EvidenceBased Best Practices. Academic Press.

Casas, J. A., Del Rey, R., \& Ortega-Ruiz, R. (2013). Bullying and cyberbullying: Convergent and divergent predictor variables. Computers in Human Behavior, 29(3), 580-587.

https://doi.org/10.1016/j.chb.2012.11.015

Chen, Q., Lo, C. K. M., Zhu, Y., Cheung, A., Chan, K. L., \& Ip, P. (2018). Family poly-victimization and cyberbullying among adolescents in a Chinese school sample. Child Abuse \& Neglect, 77, 180-187. https://doi.org/10.1016/j.chiabu.2018.01.015

Chu, X. W., Fan, C. Y., Liu, Q. Q., \& Zhou, Z. K. (2018). Cyberbullying victimization and symptoms of depression and anxiety among Chinese adolescents: Examining hopelessness as a mediator and selfcompassion as a moderator. Computers in Human Behavior, 86, 377-386.

Clark, C. M., Werth, L., \& Ahten, S. (2012). Cyberbullying and Incivility in the Online Learning Environment, Part 1: Addressing Faculty and Student Perceptions. Nurse Educator, 37(4), 150. https://doi.org/10.1097/NNE.0b013e31825a87e5

Del Rey, R., Casas, J. A., Ortega-Ruiz, R., SchultzeKrumbholz, A., Scheithauer, H., Smith, P., ... Plichta, P. (2015). Structural validation and cross-cultural robustness of the European Cyberbullying Intervention Project Questionnaire. Computers in Human Behavior, 50, 141-147.

https://doi.org/10.1016/j.chb.2015.03.065 
Doane, A. N., Boothe, L. G., Pearson, M. R., \& Kelley, M. L. (2016). Risky electronic communication behaviors and cyberbullying victimization: An application of Protection Motivation Theory. Computers in Human Behavior, 60, 508-513.

Doane, A. N., Boothe, L. G., Pearson, M. R., \& Kelley, M. L. (2016). Risky electronic communication behaviors and cyberbullying victimization: An application of Protection Motivation Theory. Computers in Human Behavior, 60, 508-513. https://doi.org/10.1016/j.chb.2016.02.010

Doane, A. N., Pearson, M. R., \& Kelley, M. L. (2014). Predictors of cyberbullying perpetration among college students: An application of the Theory of Reasoned Action. Computers in Human Behavior, 36, 154-162. https://doi.org/10.1016/j.chb.2014.03.051

Ekstrom, R. B. (1986). Who drops out of high school and why? Findings from a national study. Teachers College Record, 87(3), 356-73.

Elipe, P., Mora-Merchán, J. A., Ortega-Ruiz, R., \& Casas, J. A. (2015). Perceived emotional intelligence as a moderator variable between cybervictimization and its emotional impact. Frontiers in Psychology, 6. https://doi.org/10.3389/fpsyg.2015.00486

Farley, S., Coyne, I., Sprigg, C., Axtell, C., \& Subramanian, G. (2015). Exploring the impact of workplace cyberbullying on trainee doctors. Medical Education, 49(4), 436-443.

https://doi.org/10.1111/medu.12666

Feinstein, B. A., Bhatia, V., \& Davila, J. (2014). Rumination mediates the association between cybervictimization and depressive symptoms. Journal of Interpersonal Violence, 29(9), 1732-1746.

Forssell, R. (2016). Exploring cyberbullying and faceto-face bullying in working life - Prevalence, targets and expressions. Computers in Human Behavior, 58, 454-460. https://doi.org/10.1016/j.chb.2016.01.003

France, K., Danesh, A., \& Jirard, S. (2013). Informing aggression-prevention efforts by comparing perpetrators of brief vs. extended cyber aggression. Computers in Human Behavior, 29(6), 2143-2149. https://doi.org/10.1016/j.chb.2013.05.011

Gibb, Z. G., \& Devereux, P. G. (2016). Missing link: Exploring repetition and intentionality of distress in cyberbullying behaviors within a college population. Translational Issues in Psychological Science, 2(3), 313.

Giumetti, G. W., Hatfield, A. L., Scisco, J. L., Schroeder, A. N., Muth, E. R., \& Kowalski, R. M. (2013). What a rude e-mail! Examining the differential effects of incivility versus support on mood, energy, engagement, and performance in an online context. Journal of Occupational Health Psychology, 18(3), 297.
González-Cabrera, J., Calvete, E., León-Mejía, A., Pérez-Sancho, C., \& Peinado, J. M. (2017). Relationship between cyberbullying roles, cortisol secretion and psychological stress. Computers in Human Behavior, 70, 153-160.

https://doi.org/10.1016/j.chb.2016.12.054

Hamm, M. P., Newton, A. S., Chisholm, A., Shulhan, J., Milne, A., Sundar, P., ... \& Hartling, L. (2015). Prevalence and effect of cyberbullying on children and young people: A scoping review of social media studies. JAMA pediatrics, 169(8), 770-777.

Hancock, P. A., \& Warm, J. S. (2003). A dynamic model of stress and sustained attention. Journal of Human Performance in Extreme Environments, 7(1), 4.

Harter, S. (1999). The construction of the self: A developmental perspective. New York, NY, US: Guilford Press.

Heiman, T., Olenik-Shemesh, D., \& Eden, S. (2015). Cyberbullying involvement among students with ADHD: relation to loneliness, self-efficacy and social support. European Journal of Special Needs Education, 30(1), 15-29.

https://doi.org/10.1080/08856257.2014.943562

Herrera-López, M., Casas, J. A., Romera, E. M., Ortega-Ruiz, R., \& Del Rey, R. (2017). Validation of the European Cyberbullying Intervention Project Questionnaire for Colombian Adolescents. Cyberpsychology, Behavior and Social Networking, 20(2), 117-125.

https://doi.org/10.1089/cyber.2016.0414

Hobfoll, S. E. (1989). Conservation of resources: A new attempt at conceptualizing stress. American psychologist, 44(3), 513.

Hojat, M. (1982). Loneliness as a function of selected personality variables. Journal of Clinical Psychology, 38(1), 137-141.

Hong, J.-C., Chien-Hou, L., Hwang, M.-Y., Hu, R.-P., \& Chen, Y.-L. (2014). Positive affect predicting worker psychological response to cyber-bullying in the hightech industry in Northern Taiwan. Computers in Human Behavior, 30, 307-314.

https://doi.org/10.1016/j.chb.2013.09.011

Hu, Q., Bernardo, A. B. I., Lam, S. W., \& Cheang, P. K. (2018). Individualism-Collectivism Orientations and Coping Styles of Cyberbullying Victims in Chinese Culture. Current Psychology, 37(1), 65-72. https://doi.org/10.1007/s12144-016-9490-7

İçellioğlu, S., \& Özden, M. S. (2014). Cyberbullying: A new kind of peer bullying through online technology and its relationship with aggression and social anxiety. Procedia-Social and Behavioral Sciences, 116, 42414245. 
Jenaro, C., Flores, N., \& Frías, C. P. (2018). Systematic review of empirical studies on cyberbullying in adults: What we know and what we should investigate. Aggression and Violent Behavior, 38, 113-122.

https://doi.org/10.1016/j.avb.2017.12.003

Kaslow, N.J., Rehm, L.P., Pollack, S.L., \& Siegel, A.W. (1984). Attributional style and self-control behaviour in depressed and non-depressed children and their parents. Unpublished manuscript, University of Houston, TX.

Kırcaburun, K., Kokkinos, C. M., Demetrovics, Z., Király, O., Griffiths, M. D., \& Çolak, T. S. (2018). Problematic online behaviors among adolescents and emerging adults: Associations between cyberbullying perpetration, problematic social media use, and psychosocial factors. International Journal of Mental Health and Addiction, 1-18.

Lachman, M. E., \& Weaver, S. L. (1998). The sense of control as a moderator of social class differences in health and well-being. Journal of personality and social psychology, 74(3), 763.

Lovibond, P. F., \& Lovibond, S. H. (1995). The structure of negative emotional states: Comparison of the Depression Anxiety Stress Scales (DASS) with the Beck Depression and Anxiety Inventories. Behaviour Research and Therapy, 33(3), 335-343. https://doi.org/10.1016/0005-7967(94)00075-U

Mahatanankoon, P., \& O'Sullivan, P. (2008). Attitude toward mobile text messaging: An expectancy-based perspective. Journal of Computer-Mediated Communication, 13(4), 973-992.

McHugh, B. C., Wisniewski, P., Rosson, M. B., \& Carroll, J. M. (2018). When social media traumatizes teens: The roles of online risk exposure, coping, and post-traumatic stress. Internet Research, 28(5), 11691188. https://doi.org/10.1108/IntR-02-2017-0077

Mitchell, S. M., Seegan, P. L., Roush, J. F., Brown, S. L., Sustaíta, M. A., \& Cukrowicz, K. C. (2018). Retrospective Cyberbullying and Suicide Ideation: The Mediating Roles of Depressive Symptoms, Perceived Burdensomeness, and Thwarted Belongingness. Journal of Interpersonal Violence, 33(16), 2602-2620. https://doi.org/10.1177/0886260516628291

Mitchell, S. N., \& Hoff, D. L. (2009). Cyberbullying: causes, effects, and remedies. Journal of Educational Administration, 47(5), 652-665.

https://doi.org/10.1108/09578230910981107

Muller, R. D., Skues, J. L., \& Wise, L. Z. (2017). Cyberbullying in Australian primary schools: how victims differ in attachment, locus of control, selfesteem, and coping styles compared to non-victims. Journal of Psychologists and Counsellors in Schools, 27(1), 85-104.
Nicolai, S., Geffner, R., Stolberg, R., \& Yaruss, J. S. (2018). Retrospective Experiences of Cyberbullying and Emotional Outcomes on Young Adults Who Stutter. Journal of Child \& Adolescent Trauma, 11(1), 27-37. https://doi.org/10.1007/s40653-018-0208-x

Nixon, C. L. (2014). Current perspectives: the impact of cyberbullying on adolescent health. Adolescent Health, Medicine and Therapeutics, 5, 143-158. https://doi.org/10.2147/AHMT.S36456

Parkitny, L., \& McAuley, J. (2010). The Depression Anxiety Stress Scale (DASS). Journal of Physiotherapy, 56(3), 204.

https://doi.org/10.1016/S1836-9553(10)70030-8

Patchin, J. W., \& Hinduja, S. (2010). Cyberbullying and Self-Esteem*. Journal of School Health, 80(12), 614621. https://doi.org/10.1111/j.1746-1561.2010. 00548.x

Rotter, J. B. (1966). Generalized expectancies for internal versus external control of reinforcement. Psychological monographs: General and applied, 80(1), 1.

Rutter, M. (1985). Resilience in the face of adversity: Protective factors and resistance to psychiatric disorder. The British Journal of Psychiatry, 147, 598611.

Seigfried-Spellar, K. C., O'Quinn, C. L., \& Treadway, K. N. (2015). Assessing the relationship between autistic traits and cyberdeviancy in a sample of college students. Behaviour \& Information Technology, 34(5), 533-542.

https://doi.org/10.1080/0144929X.2014.978377

Selkie, E. M., Kota, R., Chan, Y.-F., \& Moreno, M. (2015). Cyberbullying, Depression, and Problem Alcohol Use in Female College Students: A Multisite Study. Cyberpsychology, Behavior, and Social Networking, 18(2), 79-86.

https://doi.org/10.1089/cyber.2014.0371

Tennant, J. E., Demaray, M. K., Coyle, S., \& Malecki, C. K. (2015). The dangers of the web: Cybervictimization, depression, and social support in college students. Computers in Human Behavior, 50, 348-357. https://doi.org/10.1016/j.chb.2015.04.014

Tiffany, F. (2018). Cyberbullying: A narrative review. Journal of Addiction Therapy and Research, 2(1), 010 027. https://doi.org/10.29328/journal.jatr.1001007

Tokunaga, R. S. (2010). Following you home from school: A critical review and synthesis of research on cyberbullying victimization. Computers in human behavior, 26(3), 277-287.

Tomşa, R., Jenaro, C., Campbell, M., \& Neacşu, D. (2013). Student's experiences with traditional bullying and cyberbullying : findings from a Romanian sample. Procedia - Social and Behavioral Sciences, 78, 586590. 
Trivits, L. (2005). A comparison of coping and coping resources in at-risk and seriously delinquent female adolescents. University of Virginia.

Vranjes, I., Baillien, E., Vandebosch, H., Erreygers, S., \& Witte, H. D. (2018). Kicking someone in cyberspace when they are down:Testing the role of stressor evoked emotions on exposure to workplace cyberbullying. Work \& Stress, 32(4), 379-399. https://doi.org/10.1080/02678373.2018.1437233

Wade, A., \& Beran, T. (2011). Cyberbullying: The New Era of Bullying. Canadian Journal of School Psychology, 26(1), 44-61. https://doi.org/10.1177/0829573510396318

Williams, K. D., \& Carter-Sowell, A. R. (2009). Marginalization through social ostracism: Effects of being ignored and excluded. Coping with minority status: Responses to exclusion and inclusion, 104122.

Ye, Y., \& Lin, L. (2015). Examining relations between locus of control, loneliness, subjective well-being, and preference for online social interaction. Psychological reports, 116(1), 164-175. 